\title{
Relationship between concentration of ATP in latex and yield potential in seedlings of Hevea brasiliensis and its implications in breeding
}

\author{
C. Narayanan* and S. Sreelatha \\ Rubber Research Institute of India, Kottayam-686 009, Kerala, India.
}

(Manuscript Received: 23-04-2021, Revised: 28-06-2021, Accepted: 02-07-2021)

Keywords: Full-sibs, half-sibs, Hevea, juvenile yield, latex [ATP], polycross progenies, seedling nursery

In Hevea brasiliensis, the Para rubber tree, as in many other perennial trees, the breeding programme is a long-term strategy. It takes almost 23 years before any superior clone is released for commercial planting (Simmonds, 1989; Mydin, 2014). Utility of several physiological, molecular and biochemical parameters influencing rubber yield as early screening tools were investigated, and concentration of adenosine triphosphate (ATP) in latex was found as a potential marker for high yield considering its central regulatory role in energy metabolism-related to rubber biosynthesis (Sreelatha et al., 2004). Tapping or extraction of latex through the wounding of bark involves intense metabolic processes. These dynamic metabolic processes include rubber biosynthesis and reconstitution of sub-cellular components during latex removal by tapping, which involves a constant supply of energy in the form of ATP. The supply of sucrose and the availability of ATP plays a significant role in the latex regeneration processes. ATP is a source of energy for the mobilization of different solutes across lutoid membrane (Marin et al., 1981). Thus, high latex [ATP] could be an indicator for high rubber yield in Hevea (Sreelatha et al., 2004).

Previous studies using clones of Hevea have already demonstrated that high yielding clones possessed high latex [ATP]. Using clones with variable rubber yields, it was demonstrated that high-yielding clones RRII 105 and RRIM 600 also possessed high [ATP] (Sreelatha et al., 2004). The above study also showed that low yielding clones had very low [ATP]. In another study using immature plants and trees of ten clones with variable rubber yield, it was shown that high yielding clones like RRII 105, RRIM 600, PB 217 and PB 235 displayed consistently high [ATP]. In the same study, low yielding clones like RRII 33 and RRII 38 also had low [ATP], thus strengthening the view that high latex [ATP] could be an indicator of high rubber yield in Hevea. In a recent study, latex [ATP] was shown to have a significant positive correlation with crop efficiency of the polyclonal population $(\mathrm{r}=0.76)$ and selected genotypes $(\mathrm{r}=0.61)$ (Dey et al., 2018). However, so far, no studies have been carried out to assess the relationship between latex [ATP] and corresponding juvenile yield potential using seedlings.

In the Hevea breeding programme, 'test-tap' or juvenile yield has been used as an estimator of yield in young plants of $H$. brasiliensis (Varghese et al., 1989). Test tapping is carried out in two to threeyear-old plants in a nursery, and the selections are evaluated in mature clonal trials after vegetative multiplication through budding (Mydin and Saraswathyamma, 2005). Previous studies have used mature trees of clonal and polyclonal origin for studying the relationship between yield based on normal tapping and latex [ATP] (Sreelatha et al., 2014; Dey et al., 2018). In the present study, we investigated the relationship between test-tap yield

*Corresponding Author: cnarayanan@rubberboard.org.in 
potential and corresponding latex [ATP] using a seedling population in a nursery evaluation trial.

The experimental population comprised of seedling progenies (full-sibs, half-sibs and openpollinated polycross progenies), which were evaluated in a nursery trial in the farm of Rubber Research Institute of India (Kottayam, Kerala state, India). Details of the progenies and their pedigree are given in Table 1. Standard procedures were followed for assessing the juvenile yield through test-tapping (Mydin and Saraswathyamma, 2005). The progenies were planted at a spacing of $60 \mathrm{~cm} \mathrm{x}$ $60 \mathrm{~cm}$, and test-tapping was carried out at a height of $20 \mathrm{~cm}$ from ground level. After discarding latex from the first five test-tappings, latex from the subsequent 15 test tappings were collected, air-dried and weighed to compute mean test-tap yield as grams per tree per $\operatorname{tap}\left(\mathrm{g} \mathrm{tree}^{-1} \operatorname{tap}^{-1}\right)$. Test tapping was initiated from the third year of planting, and the yield recording was continued for two more years. ATP concentration in latex was determined in the third year of test-tapping (Amalou et al., 1992; Sreelatha et al., 2014). Data on test-tap yield and latex [ATP] of progenies were regressed to find the correlation.

Mean test-tap yield and latex [ATP] of the progenies are given in Table 2. Test-tap yield ranged from 0.3 to $31.5 \mathrm{~g}$ tree $^{-1}$ tap $^{-1}$, indicating very high variability in the experimental population (Table 2). Among full-sibs, 14/C33 (RRII 414 x 90/21), followed by 14/A216 (RRII 414 x RO 230), recorded a high mean yield of $31.5 \mathrm{~g} \mathrm{tree}^{-1}$ tap $^{-1}$ and $19.1 \mathrm{~g}$ tree $^{-1}$ tap $^{-1}$, respectively. Among hybrids of RRII 105, one hybrid (14/A143) gave a mean yield of $4.8 \mathrm{~g} \mathrm{tree}^{-1} \mathrm{tap}^{-1}$. The remaining two hybrids, 14/A240 and 14/A236 recorded very low mean yields ranging from 0.3 to $1.0 \mathrm{~g}_{\text {tree }}^{-1} \mathrm{tap}^{-1}$.

Half-sibs of Fx 516 had a mean yield ranging from 9.5 in 14/HS/Fx516/D5 to $28.2 \mathrm{~g} \mathrm{tree}^{-1}$ tap $^{-1}$ in 14/HS/Fx516/D3. Similarly, there was a wide variation in yield among half-sibs of RRII 430 and RRII 414. The mean yield of half-sibs of RRII 414 ranged from 6.6 in 14/HS/RRII414/D205 to $13.6 \mathrm{~g}$ tree $^{-1}$ tap $^{-1}$ in 14/HS/RRII414/D97. Half-sibs of RRII 430 had a mean yield ranging from 5.9 in $14 / \mathrm{HS} /$ RRII430/D83 to $29.9 \mathrm{~g}$ tree $^{-1}$ tap $^{-1}$ in 14/HS/RRII430/ C64. The half-sib of $H$. spruceana (14/HS/HSP/ A154) gave the lowest yield of $0.4 \mathrm{~g} \mathrm{tree}^{-1} \operatorname{tap}^{-1}$.

Progenies exhibited very high variation for latex [ATP] (Table 2). Maximum ATP concentration
Table 1. Details of progenies and their parentage

\begin{tabular}{|c|c|}
\hline Progeny identity & Parentage \\
\hline 14/HS/Fx516/D3 & HS of Fx 516 (F 4542 x AVROS 363) \\
\hline 14/HS/Fx516/A248 & HS of Fx 516 \\
\hline 14/HS/Fx516/A95 & HS of Fx 516 \\
\hline 14/HS/Fx516/D5 & HS of Fx 516 \\
\hline 14/HS/HSP/A154 & HS of H. spruceana \\
\hline 14/HS/RRII414/C3 & HS of RRII 414 (RRII 105 x RRIC 100) \\
\hline 14/HS/RRII414/D97 & HS of RRII 414 \\
\hline 14/HS/RRII414/D205 & HS of RRII 414 \\
\hline 14/HS/RRII414/D214 & HS of RRII 414 \\
\hline 14/HS/RRII414/D209 & HS of RRII 414 \\
\hline 14/HS/RRII414/C5 & HS of RRII 414 \\
\hline 14/HS/RRII414/D215 & HS of RRII 414 \\
\hline 14/HS/RRII430/C48 & HS of RRII 430 (RRII 105 x RRIC 100) \\
\hline 14/HS/RRII430/D248 & HS of RRII 430 \\
\hline 14/HS/RRII430/C64 & HS of RRII 430 \\
\hline 14/HS/RRII430/D142 & HS of RRII 430 \\
\hline 14/HS/RRII430/D231 & HS of RRII 430 \\
\hline 14/HS/RRII430/D226 & HS of RRII 430 \\
\hline 14/HS/RRII430/D19 & HS of RRII 430 \\
\hline 14/HS/RRII430/D227 & HS of RRII 430 \\
\hline 14/HS/RRII430/D26 & HS of RRII 430 \\
\hline 14/HS/RRII430/D78 & HS of RRII 430 \\
\hline 14/HS/RRII430/D225 & HS of RRII 430 \\
\hline 14/HS/RRII430/D66 & HS of RRII 430 \\
\hline 14/HS/RRII430/D83 & HS of RRII 430 \\
\hline 14/HS/RRII430/D250 & HS of RRII 430 \\
\hline 14/HS/RRII430/D71 & HS of RRII 430 \\
\hline 14/HS/RRII430/D138 & HS of RRII 430 \\
\hline 14/OP/OPCES/A197 & Polycross progeny \\
\hline 14/A143 & RRII 105 (Tjir 1 x Gl 1) x Fx 516 \\
\hline 14/A240 & RRII 105 x RO 230 \\
\hline 14/A236 & RRII 105 x RO 230 \\
\hline 14/C33 & RRII 414 x 90/21 (RRII 105 x RO 142) \\
\hline 14/A216 & RRII 414 x RO 230 \\
\hline
\end{tabular}

(375.5 $\mu \mathrm{M})$ was detected in $14 / \mathrm{C} 33$, which also possessed the maximum rubber yield $\left(31.5 \mathrm{~g}\right.$ tree $^{-1}$ tap $\left.^{-1}\right)$. Very low [ATP] $(46 \mu \mathrm{M})$ was recorded in $14 /$ A236 (RRII 105 x RO 230), which also had a very low rubber yield of $1.0 \mathrm{~g}^{\text {tree }} \mathrm{tap}^{-1}$. Very low yielding progenies 14/A240 (RRII 105 x RO 230; $0.3 \mathrm{~g} \mathrm{tree}^{-1} \mathrm{tap}^{-1}$ ) and 14/HS/HSP/A154 (half-sib of H. spruceana; $0.5 \mathrm{~g}$ tree $^{-1}$ tap $^{-1}$ ) also had very low [ATP] of 80 and $53 \mu \mathrm{M}$, respectively. Overall, high- 
Table 2. Juvenile test-tap yield and latex [ATP] of progenies.

\begin{tabular}{|c|c|c|}
\hline Progeny & $\begin{array}{l}\text { Test-tap yield } \\
\left(\mathrm{g} \mathrm{tree}^{-1} \text { tap }^{-1}\right)^{*, \#}\end{array}$ & $\begin{array}{c}\text { Latex } \\
{[\mathrm{ATP}](\mu \mathrm{M})}\end{array}$ \\
\hline 14/C33 & 31.5 & 375.7 \\
\hline 14/HS/RRII430/C64 & 29.9 & 309.9 \\
\hline 14/HS/Fx516/D3 & 28.2 & 315.3 \\
\hline 14/HS/RRII430/C48 & 28.0 & 355.2 \\
\hline 14/A216 & 19.1 & 268.1 \\
\hline 14/HS/Fx516/A248 & 19.0 & 305.9 \\
\hline 14/HS/RRII430/D227 & 18.1 & 206.1 \\
\hline 14/HS/RRII430/D142 & 17.3 & 266.8 \\
\hline 14/HS/RRII430/D19 & 16.6 & 206.3 \\
\hline 14/HS/RRII430/D26 & 15.0 & 202.9 \\
\hline 14/HS/RRII430/D78 & 14.9 & 193.0 \\
\hline 14/HS/RRII430/D248 & 14.8 & 339.0 \\
\hline 14/HS/RRII430/D66 & 14.1 & 171.0 \\
\hline 14/HS/RRII414/D97 & 13.6 & 261.7 \\
\hline 14/OP/OPCES/A197 & 13.0 & 241.3 \\
\hline 14/HS/RRII414/C3 & 12.8 & 359.4 \\
\hline 14/HS/RRII430/D231 & 12.4 & 240.2 \\
\hline 14/HS/Fx516/A95 & 12.2 & 273.4 \\
\hline 14/HS/RRII430/D71 & 11.6 & 141.7 \\
\hline 14/HS/RRII430/D225 & 11.4 & 173.4 \\
\hline 14/HS/RRII414/D209 & 11.2 & 145.4 \\
\hline 14/HS/RRII430/D138 & 11.2 & 122.6 \\
\hline 14/HS/RRII414/D215 & 10.8 & 122.3 \\
\hline 14/HS/RRII430/D226 & 10.2 & 215.6 \\
\hline 14/HS/Fx516/D5 & 9.5 & 134.0 \\
\hline 14/HS/RRII414/C5 & 8.7 & 124.4 \\
\hline 14/HS/RRII414/D214 & 7.0 & 171.8 \\
\hline 14/HS/RRII430/D250 & 7.0 & 161.6 \\
\hline 14/HS/RRII414/D205 & 6.6 & 182.3 \\
\hline 14/HS/RRII430/D83 & 5.9 & 164.0 \\
\hline 14/A143 & 4.8 & 124.3 \\
\hline 14/A236 & 1.0 & 46.1 \\
\hline 14/HS/HSP/A154 & 0.4 & 52.9 \\
\hline $14 / \mathrm{A} 240$ & 0.3 & 79.9 \\
\hline Mean & 13.2 & 207.5 \\
\hline Range & $0.3-31.5$ & $46.1-375.7$ \\
\hline S.E. & 1.3 & 15.1 \\
\hline
\end{tabular}

*Mean over three years; "Progenies are listed in descending order, based on their yield performance. yielding half-sib selections of RRII 414, RRII 430 and Fx 516 also had very high latex [ATP] of more than $300 \mu \mathrm{M}$.

Regression analysis revealed a direct relationship $\left(\mathrm{R}^{2}=0.66\right)$ between latex $[$ ATP $]$ and testtap yield of the progenies (Fig. 1), which conformed with the earlier findings from investigations with clones (Sreelatha et al., 2014; Dey et al., 2018). In general, high-yielding progenies had more latex [ATP] than low-yielders and vice versa. ATP is a direct source of energy for the conversion of sucrose to poly-isoprene molecules (rubber). It indirectly affects rubber yield, mediated through lutoid membrane ATPase activity (Sreelatha et al., 2014). Hence, higher levels of ATP in latex of high yielding progenies indicated that ATP could be involved in increasing the efficiency of rubber biosynthesis, as reported earlier (Sreelatha et al., 2014).

Presently, 'test tapping' or juvenile tapping of seedlings at the age of two to three years in the nursery stage is the only recommended strategy for early screening of large populations for assessing their yield potential and shortlisting the selections before proceeding to further clonal evaluation $(\mathrm{Ho}$, 1976; Tan, 1987). Only a very low percentage of selections (based on test-tap yield) from seedling nurseries turned into high yielders. Test-tapping is mandatory and cannot be dispensed with until more reliable methods for phenotype selection are evolved (Mydin, 2012). Nevertheless, the correlations between nursery yield (based on test-tapping) and mature yield though significant, are still not very strong enough ( $r=0.22$ to 0.26$)$ to make juvenile yield evaluation by test-tapping alone a completely reliable method for early selection as only 25 per cent of selections from seedlings gave significantly higher yield at mature stages (Tan, 1998; Mydin, 2012). Thus, more detailed information on major yield components and stable sub-components, including biochemical components in the immature phase, could help evolve more reliable parameters for early prediction of yield with more precision (Licy et al., 1998; Prabhakaran Nair, 2010).

Although the high correlation between latex [ATP] and mature yield has already been established using clones of various ages and mature polycross population (Sreelatha et al., 2004, Sreelatha et al. 2014, Dey et al., 2018), so far, no such studies have been carried out using young seedlings. The present study conducted using nursery seedlings of a heterogeneous population consisting of half-sib, fullsib and polycross progenies similarly demonstrated 


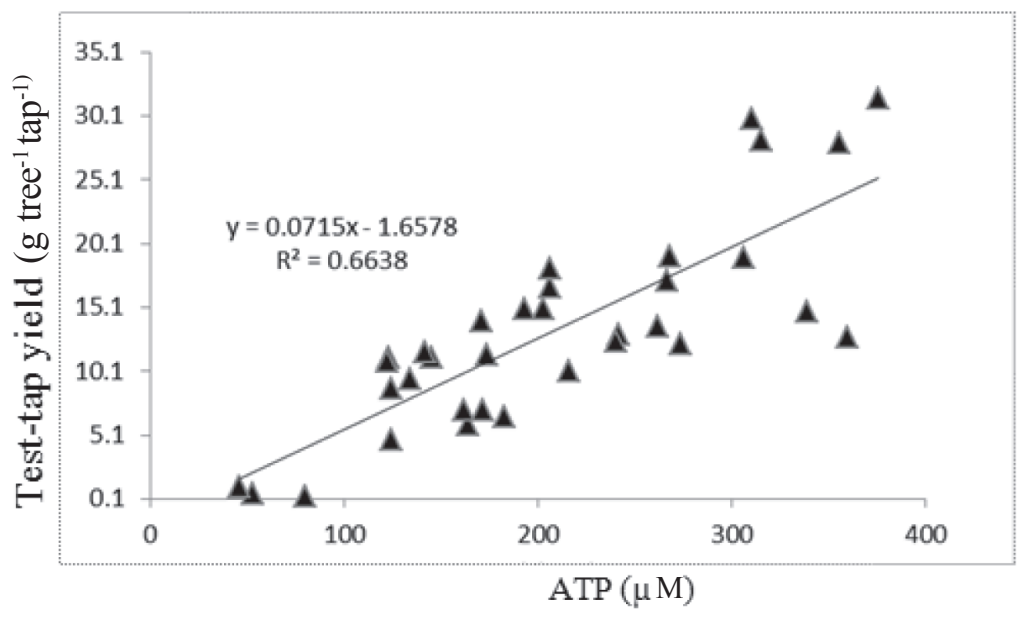

Fig. 1. Relationship between test-tap yield and latex [ATP]

a very strong relationship between juvenile test-tap yield and latex [ATP] irrespective of sibling composition. Thus, only seedlings with high test-tap yield and high latex [ATP] should be selected in order to ensure more precision in the recovery of high yielding genotypes to forward them to subsequent stages of clonal evaluation in larger field trials.

\section{Acknowledgement}

The authors are thankful to Dr. James Jacob for his critical review and valuable suggestions for improving the manuscript.

\section{References}

Amalou, Z., Bangratz, J. and Chrestin, H. 1992. Ethrel (Ethylene releaser) induced increase in the adenylate pool and transtonoplast $\mathrm{pH}$ within Hevea latex cells. Plant Physiology 98: 1270-1276.

Varghese, Y. A., Licy, J., John, A. and Panikkar, A. O. N. 1989. An incision method for early selection of Hevea seedlings. Indian Journal of Natural Rubber Research 2: 112-117.

Dey, S. K., Antony, P. D. and Mehra, B. K. 2018. [ATP] content of latex as a marker for high rubber yield in clones grown in north-eastern region of India. Rubber Science 31: 22-30.

Ho, C. Y. 1976. Clonal characters determining the yield of Hevea brasiliensis. In: Proceedings of international rubber conference. Kuala Lumpur: Rubber Research Institute of Malaysia, Kuala Lumpur, pp. 17-38.

Licy, J., Thomas, M., Saraswathyamma, C. K. and Sethuraj, M. R. 1998. Studies on biochemical subcomponenets of latex for crop improvement in Hevea. 1998. In: National Symposium on Current Trends in Plant Physiology and
Plant Biochemistry, Department of Plant Science, University of Hyderabad, India. p. 161.

Marin, B., Lanza, M. and Komor, E. 1981. The proton motive difference across the vacuo-lysosomal membrane of Hevea brasiliensis (Rubber tree) and its modification by a membrane bound adenosine tri phosphatase. Biochemical Journal 198: 365-372.

Mydin, K. K. 2012. Juvenile-mature correlations and associations among rubber yield and yield attributes in Hevea brasiliensis. Natural Rubber Research 25: 1-12.

Mydin, K. K. 2014. Genetic improvement of Hevea brasiliensis: sixty years of breeding efforts in India. Rubber Science 27: 153-181.

Mydin, K. K. and Saraswathyamma, C. K. 2005. Hevea Breeding Manual. Rubber Research Institute of India, Kottayam, India, 97 p.

Prabhakaran Nair, K. P. 2010. Rubber (Hevea brasiliensis). In: The Agronomy and Economy of Important Tree Crops of the Developing World, (Ed.) Prabhakaran Nair, K. P. London: Elsevier Press, pp. 237-273.

Simmonds, N. W. 1989. Rubber breeding. In Rubber, (Ed.) Webster, C. C. and Baulkwill, W. J. USA: Longman scientific and technical, pp. 85-124.

Sreelatha, S., Simon, S.P. and Jacob, J. 2004. On the possibility of using latex ATP concentration as an indicator of high yield in Hevea. Journal of Rubber Research 7: 71-78.

Sreelatha, S., Jacob, J., Mercykutty, V. C., Simon, S. P., Krishnakumar, R. and Annamalainathan, K. 2014. ATP concentration in latex as an indicator for early evaluation of yield in Hevea brasiliensis. Journal of Plantation Crops 42: 48-53.

Tan, H. 1987. Strategies in rubber tree breeding. In: Improving Vegetatively Propagated Crops, (Ed.) Abbott, A.J. and Atkim, R.K. London: Academic Press, pp. 28-62.

Tan, H. 1998. A study on nursery selection in Hevea breeding. Journal of Rubber Research 1: 253-262. 